\title{
THE GROWTH RESPONSES OF ORCHID, Phalaenopsis HYBRID TO THE INOCULATION OF Rhizoctonia solani
}

\author{
NORHAYATI YUSUF*, NURUL ALIAA IDRIS and ZALIFAH KATMAN \\ Biological Security and Sustainability (BioSeS) Research Group, \\ Faculty of Science and Marine Environment, Universiti Malaysia Terengganu, \\ 21030 Kuala Nerus, Terengganu, Malaysia \\ ${ }^{*}$ E-mail: yatiyusuf@umt.edu.my
}

Accepted 25 November 2020, Published online 25 December 2020

\begin{abstract}
The orchid mycorrhizal association is a symbiotic interaction in which both plants and fungi are mutually beneficial. Mycorrhizal association increases plant access to soil nutrients and is especially important for orchid seed germination. Most orchid mycorrhizal fungi belong to the group Rhizoctonia, including Rhizoctonia solani, a well-known plant pathogen that affects major crop production worldwide but has also been reported to be an orchid mycorrhiza. However, no systematic study has been done to investigate the type of interaction that develops when pathogenic $R$. solani interact with an orchid; whether a pathogen can alter its association to become mycorrhizal. Thus, this study was conducted to determine the type of interaction between Phalaenopsis hybrid and R. solani and its effect on the growth and chlorophyll content of Phalaenopsis hybrid. Sterile ex vitro Phalaenopsis plantlets were inoculated with 4 discs $(0.5 \mathrm{~cm}$ diameter $)$ of $R$. solani, isolated from diseased rice tissues, and incubated for 9 days. The inoculated root segments were used to observe the fungal hyphae in the root cell. The growth parameters (plant height, leaves length and width, the number of leaves, fresh and dry weights) and chlorophyll content were determined at $0,3,6,7,8$, and 9 days of inoculation. It was observed that no peloton was present in the root cells of all inoculated plants. Severe reduction of growth and chlorophyll content were obtained in inoculated plants compared to control especially after 7 days of inoculation. These results suggested that $R$. solani developed a pathogenic infection to Phalaenopsis hybrid as no peloton structure was present in the root cells. $R$. solani infection also reduces the Phalaenopsis hybrids growth as well as declined its chlorophyll content.
\end{abstract}

Key words: Chlorophyll content, growth, mycorrhizae, Rhizoctonia solani, Phalaenopsis hybrid

\section{INTRODUCTION}

The Orchidaceae is the largest family in the flowering plant which includes about 30,00035,000 species over 700 genera encompassing around $10 \%$ of flowering plant species. Nevertheless, there are still hundreds of new species displaying variable floral features, lifestyles, habitat distributions, and trophic patterns that are being discovered and progressed every year (Hossain et al., 2013; Herrera et al., 2017). For many years, orchid cultivation has been developed from a hobbyist market that is becoming a highly commercial market. Despite the diversity of orchids, only a handful of genera are grown in large quantities as a commercial market such as Cymbidium, Dendrobium, Oncidium, and Phalaenopsis (Moudi et al., 2013). In Malaysia, commercial production of orchids and

\footnotetext{
* To whom correspondence should be addressed.
}

hybrids is increasing and gives a huge contribution to the economy. It was reported that from the year 2015 to 2017, the export of orchids has augmented from RM11.9 million to RM13.2 million, respectively. The orchids are marketable as ornamental plants especially for cutting flowers in Singapore, Japan, Australia, and Greece (Shabariah et al., 2017).

Orchids have several unique characteristics correlated to their reduced size of the embryo and the absence of endosperm which causes difficulty in germination (Moudi et al., 2013). Various strategies have been made to induce higher germination rates of orchid seeds. The most successful method is using symbiotic mycorrhizal fungi as well as modulating the factors for germination including nutrients, photoperiod, temperature, and plant hormones (Yamazaki \& Miyoshi, 2007; Yeh et al., 2019). The orchidmycorrhizal association is a symbiotic type that is essential for one or both partners, between fungi and 
the roots of a living plant, which is responsible for nutrients transfer (Brundrett et al., 2004). Mycorrhizae improve the plant's access to soil resources such as mineral ions and water and help the orchids to survive in an inactive state for years (Parthibhan et al., 2017). The interaction begins when the mycorrhizal fungi infect basal cells in the embryo during seed germination. The orchid digested the hyphal to obtain carbon and nutrients necessary for its development. The protocorm (heterotrophic structure) then forms the seedling. The seedling produces its first root and the fungal hyphae grow into host tissues and form specific coiled structures called pelotons within the cortical cells. From this phase, symbiosis with mycorrhizal fungi facilitates the acquisition of nutrients from the substrate (Peterson et al., 2004; Rasmussen \& Rasmussen, 2009; Dearnaley et al., 2012).

Rhizoctonia solani is the most extensively studied among Rhizoctonia species. They are widely distributed in both farmland and forests. Most of the species are pathogenic to various crops, including agronomical, ornamental, and forestry species, thus causes great losses to the yield (Agarwai et al., 2010). Symptoms of the disease caused by $R$. solani in different host plants include leaf blights, cankers lesions on sprouts, rots on roots, leaf spots, damping off, shoots and fruits, stolons, and sclerotial diseases. Remarkably, despite being pathogenic to the valuable crops, especially rice, some strains of $R$. solani were also reported to form symbiotic mycorrhizal relationships with orchid plants (Mosquera-Espinosa et al., 2013; Abdeljalil et al., 2016). Hence, it is necessary to determine whether the same fungal species but isolated from pathogenic sources can form this mycorrhizal association or remain pathogenic in the Phalaenopsis hybrid.

Losing chlorophyll content leading to necrotic lesions are frequently observed on infected leaves as an early plant response during the plant-pathogen infection. The necrotic lesions develop gradually from small green watersoaked lesions during an early infection phase and then rapidly enlarged, causing destruction and cell death (Borges et al., 2013; Aung et al., 2018). The ability of plants to withstand the pathogenic interaction is very important for plant survival. Pathogen activity resulting in damage to photosynthetic machinery, loss of photosynthetic tissue, and vasculature disorders that affect water and sugar transport, have adverse effects on photosynthesis, thus reducing its growth (Mitra \& Baldwin et al., 2014). Therefore, the purpose of this study is to determine the type of interaction between Phalaenopsis hybrid and $R$. solani and its effect on the physical appearance of Phalaenopsis hybrid. Moreover, the growth and chlorophyll content of the Phalaenopsis hybrid were also assessed.

\section{MATERIALS AND METHODS}

\section{Plant materials}

Cultures of Phalaenopsis hybrid (five-monthold) were chosen as the model plants (Figure 1). The plantlets were purchased from Phalaenopsis Waltex Biotech Sdn. Bhd. Ulu Yam, Selangor. The plantlets were transferred into $12 \mathrm{~cm}$ diameter pots filled with $3 \mathrm{~g}$ mosses and were grown in a moisture chamber for 2 weeks. Plantlets were then relocated to the greenhouse where they were acclimatized under normal daylight for 2 weeks under a plastic shaft and wetted once daily. Three replications of control and infected plants for each treatment were put on separate covered shelves. The experiments were carried out for 9 days. The growth and chlorophyll content were determined at $0,3,6,7$, 8 , and 9 days of the experimental period. The experiments were conducted using a Randomized Complete Block Design (RCBD).

\section{Rhizoctonia solani isolation}

Rhizoctonia solani were obtained from diseased rice tissues from paddy fields and was isolated at Faculty of Science and Marine Environment (FSME), Universiti Malaysia Terengganu (UMT). Segments of diseased tissues were collected and washed thoroughly under running tap water. The tissues were cut $(1 \mathrm{~cm})$ then surface sterilized with $70 \%$ ethanol for $1 \mathrm{~min}$ followed by soaking in $25 \%$ Clorox for $2 \mathrm{~min}$. Then, the tissues were rinsed with sterile distilled water 2 to 3 times. The sterilized tissues were then cultured onto potato dextrose agar (PDA) media and were incubated at $27 \pm 2{ }^{\circ} \mathrm{C}$. After 3 days of incubation, the fungi were examined under a microscope and the identification was confirmed based on cultural characteristics such as an absence of conidia, right angle hyphae, and septation in hyphal branches, mycelia contain brown shades and presence of small dark brown round shaped sclerotia (Ogoshi et al., 1975). The identified isolate was sub-cultured onto fresh PDA media to obtain a pure culture. The pure cultures of

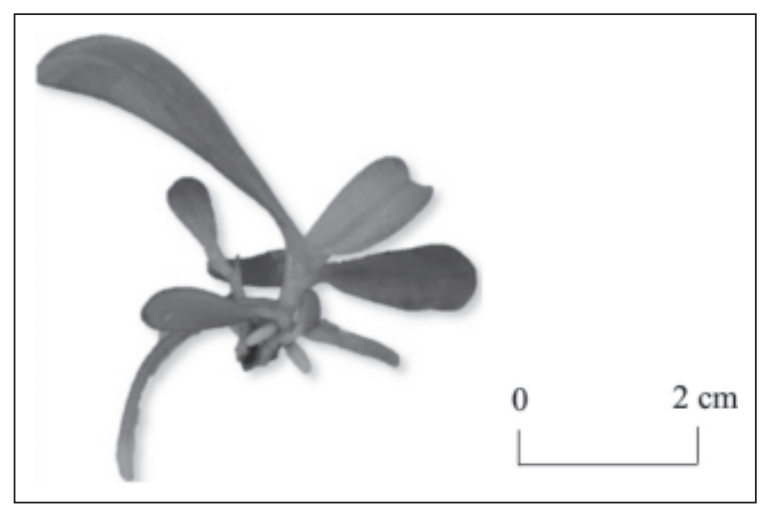

Fig. 1. Phalaenopsis hybrid. 
$R$. solani were maintained on PDA and were incubated at $27 \pm 2{ }^{\circ} \mathrm{C}$ ( 2 to 3 days) in the Microbiology Laboratory, FSME, UMT.

\section{Rhizoctonia solani inoculation}

After 2 weeks of transplantation, the moss at the base of orchid plantlets was pushed aside to uncover the portion of the root. The plantlets were inoculated with 4 discs of $R$. solani mycelia $(0.5 \mathrm{~cm}$ diameter each) which were placed near to the root at $1 \mathrm{~cm}$ from the stem. Roots were covered by moss after inoculum (Yao et al., 2002). The plant morphological changes, peloton structure observation as well as growth, and chlorophyll content were assessed at $0,3,6,7,8$, and 9 days.

\section{Screening for peloton structure}

Sections of the infected and control root segments $(1 \mathrm{~cm})$ were randomly sampled for evaluation of $R$. solani infection. The roots transverse sections were made manually using a sterile razor blade (Gillete, India) and the sections were stained with lactofuchsin (Larone, 1995). The stained roots were examined under a microscope $(100 \times)$ for the presence of peloton structure. The fungal hyphae form coiled around the plant root cells indicated the formation of peloton structure.

\section{Growth parameters}

The plant height leaves length and width of all leaves were measured using a $15 \mathrm{~cm}$ ruler. The fresh weights were obtained using an analytical balance. Plants were dried to a constant weight in an oven at $80^{\circ} \mathrm{C}$ for dry weight measurements. All the growth parameters were measured in inoculated plants as well as their respective control.

\section{Determination of chlorophyll content}

Chlorophyll content was determined based on the method by Harbone (1984). Approximately $0.15 \mathrm{~g}$ fresh leaf tissues were ground up with $6.0 \mathrm{~mL}$ of $80 \%$ acetone at $0-4^{\circ} \mathrm{C}$ in pre-chilled mortar and pestle. The mixture was centrifuged at $10000 \mathrm{rpm}$ (Eppendorf 5840R) for 10 minutes at $0-4^{\circ} \mathrm{C}$. The supernatant obtained was read at $663 \mathrm{~nm}$ and $645 \mathrm{~nm}$ using a spectrophotometer (Shimadzu UV-1601). The total chlorophyll content was calculated using the formula:

Total chlorophyll $=$

20.4 A645 + 8.67 A633 $\times$ acetone volume $(\mathrm{mL})$ $\alpha \times 1000 \mathrm{~mL} \times$ leaves weight $(\mathrm{g})$

Where $\alpha=1.0$.

\section{Statistical analysis}

Data obtained were analyzed using GraphPad Prism 5 software. The comparison of growth and chlorophyll content of Phalaenopsis hybrid were tested using two-way ANOVA at $\alpha=0.05$ as a significant level. The data were expressed as means \pm standard error.

\section{RESULTS AND DISCUSSION}

The changes in the morphological characteristic of the Phalaenopsis hybrid

The first symptoms of the infection begin with a small spot on leaves (Figure 2A) which can expand to large circular spots with concentric rings accompanied by an irregular emergence of plants. This was followed by wilting and yellowing of leaves especially after 3 days of inoculation (Figure 2B). The roots became rot and change to brown at the end of the inoculation period (Figure 2D). After 6 days of inoculation, the leaves of the Phalaenopsis hybrid showing shriveled, twisted, and thin (Figure 2C) and slowly die at 9 days of inoculation period. These results were consistent with the results obtained by Sweet and Uchida (2015) on the interaction of Fusarium spp. and Dendrobium orchid cultivar UH 800. They found that Fusarium infection usually causes leaf spots, leaf blights, or leaf rots of Dendrobium orchid. Leaves are infected when young, and the extremity of the disease is based on the age and humidity of the shoots. Foliar symptoms started with chlorotic 2-5 $\mathrm{mm}$ circular leaf spots that lead into necrotic small and sunken brown to blackish brown leaf spots. In severe infections, these spots can be fused to form blights that sometimes kill the shoot. It was also observed that the young shoots of Phalaenopsis hybrid were easily affected and may decay if infection occurs at shoot emergence. These symptoms can be caused by the production of toxic metabolites and associated with toxins that cause pathogenicity in the plants. The results of the study showed that toxins lead to the cell membrane and cytoplasm rupture (Geoffrey \& Kerstin, 2017). Thus, new growth is destroyed by $R$. solani and multiple plant deaths can cause severe losses.

\section{Type of interaction between $R$. solani with Phalaenopsis hybrid}

In this study, the first step in understanding the interactions, either mutualistic or antagonistic is the identification of the peloton structure in the root cell after inoculation with $R$. solani. Observation on the infected orchid roots showed that there was no 


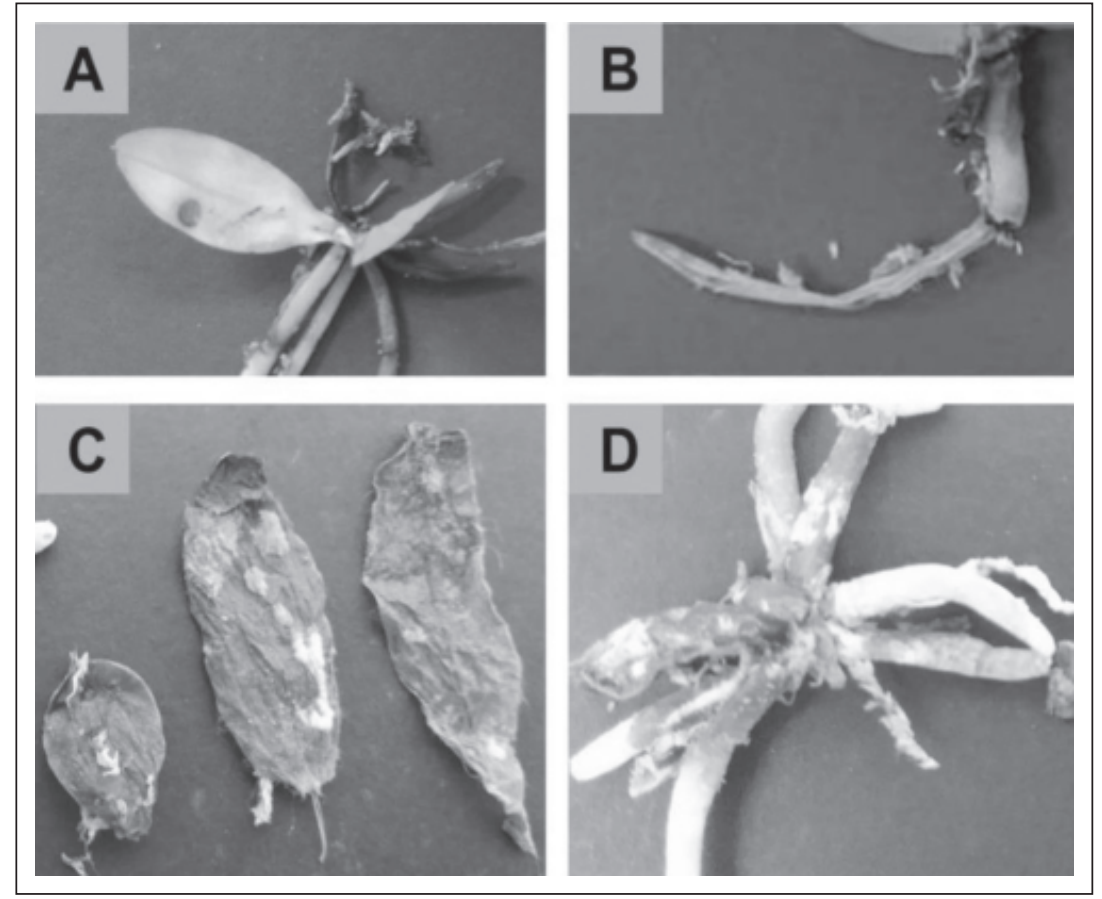

Fig. 2. Symptoms of Interaction between $R$. solani and Phalaenopsis hybrid: A) Leaves showing yellowish, leaf spots, and leaf blight. B) Root rot. C) Leaves showing shriveled, twisted, and thin. D) Brown roots.

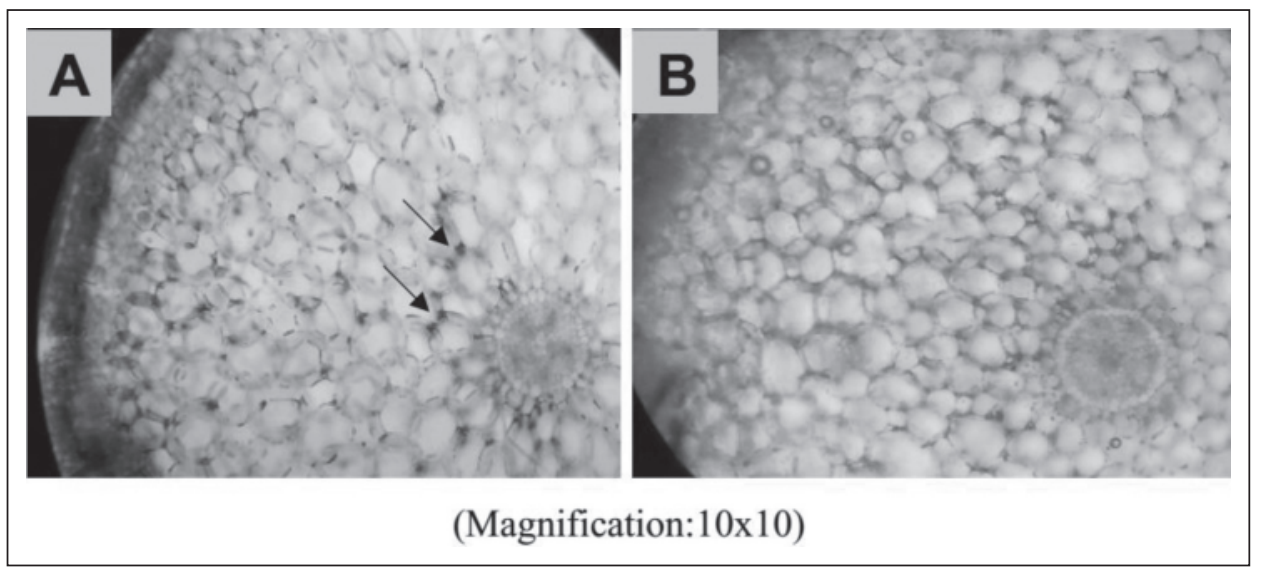

Fig. 3. Root cells of Phalaenopsis hybrid inoculated with $R$. solani (arrows point to $R$. solani compact infection cushions) (A) and control (B).

peloton formed in the root cells of Phalaenopsis, thus indicating that the interaction is pathogenic or there is no mycorrhizal symbiosis between Phalaenopsis hybrid roots with $R$. solani (Figure 3). The orchid-mycorrhizal association is a mutualistic symbiosis where both plants and fungi get benefit from each other (Abdeljalil et al., 2016). The typical indicator of an orchid mycorrhizal interaction is the presence of the structure called the peloton, which is hyphae masses of tightly interwoven coils, of which the formation is influenced by the type of orchid and orchid's habitat.
Unfortunately, the inoculated Phalaenopsis roots in this study were accompanied by the occurrence of the pathogen infection cushions in the root tissues (Figure 3A). Such an incident was also observed in root pathogens such as $F$. oxysporum as an initial event for the invasion of plant tissues (Mendgen et al., 1996). Infection cushions produced in this study enable the $R$. solani vegetative hyphae to penetrate different types of plant cell walls. The morphogenetic events leading to the formation of the infection structure often depend on specific signals provided by the plant surface and are 
prerequisites for a mode of penetration. Physiological changes such as targeted secretion of enzymes or an increase of pressure within the infection structure support the penetration process. Following this, the cell membrane disappeared, mitochondria and cell wall were no longer smooth, the shapes of chloroplast changed, and the endoplasmic reticulum swelled. Also, complete disruption was observed in the epidermal cell resulting in decay and degradation of the primary cell wall (Abdeljalil et al., 2016).

Rhizoctonia-like fungi have been previously reported as orchid mycorrhiza of the epiphytic orchids, Appendiculla sp., Calanthe vestita, and Bulbophyllum beccarii (Suryantini et al., 2015). In contrast, some of the epiphytic orchids were also found to be pathogenic in Cattleya skinneri, C. aurantiaca, and Brassavola nodosa with Rhizoctonia fungus (Ovando et al., 2005) as observed in this study. No peloton structures spotted in this study might be related to the fungi toxic phytoalexins, cell wall-degrading enzymes, and defense mechanism activation during plantpathogen interaction, therefore control or limit colonization of fungal (Quoc \& Chau et al., 2017).

\section{Effect of Rhizoctonia solani inoculation on the growth of Phalaenopsis hybrid}

Rhizoctonia solani infection did not significantly affect $(p>0.05)$ plant growth parameters at earlier stages of experimental periods except for plant height. Fresh and dry weights of Phalaenopsis were unaffected at 0 to 7 days of experiments; however, the fresh and dry weights of control plants were significantly higher $(p<0.05)$ compared with inoculated plants after 7 days of experiments (Figures 4 \& 5). Daami-Remadi et al. (2008) also reported similar observations when a significant reduction in fresh and dry weights of potato,

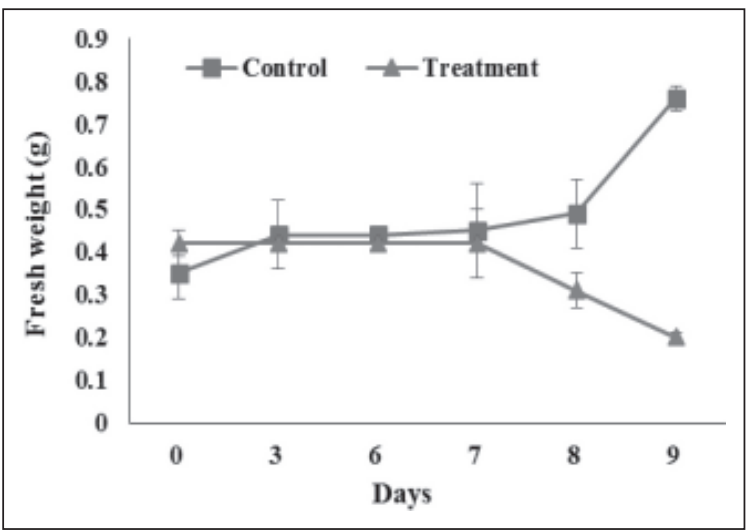

Fig. 4. Changes in fresh weight (g) of Phalaenopsis hybrids inoculated with $R$. solani and control. Data are means \pm standard errors $(n=3)$.
Solanum tuberosum infection with $R$. solani. This may be related due to starch translocation and nutrient movement from leaves to roots leading to these reduce yields. The decrease in the dry matter content of the plant in this study indicates that less biomass was transported into the generative organs during the growth period of the plants (Lemoine et al., 2013). All these features were promptly related to the photosynthesis rates of the plants. A previous report by Debona et al. (2014) revealed that reductions in photosynthesis may be proportional to decreases in yield of wheat plants infected with Pyricularia oryzae. Fungal infection can also affect the net carbon assimilation rate by increasing leaf respiration, which is necessary for supplying the demand caused by the accelerated metabolic activity of the host cells (Lucas et al., 1998).

Figures $6 \& 7$ illustrate the changes in leaf width and leaf length of Phalaenopsis hybrid inoculated with $R$. solani and its respective controls. The leaf width and leaf length of Phalaenopsis hybrid were not significantly affected $(p>0.05)$ by $R$. solani inoculation throughout 6 and 7 days of inoculation, respectively. The leaf width of control plants increased significantly $(p<0.05)$ after 6 days of inoculation periods whereas the inoculated leaves slowly decreased. Alternatively, leaf length was remarkably decreased in inoculated plants compared with control. The results obtained in this study were parallel with the research by Sandras et al. (2010). They found that the fungus Verticillium dahliae significantly reduces the total photosynthetic leaf area on the sunflower plant at 50 days after inoculation. It was postulated that during the infection process, the plant tries to cope with the situation by decreasing its leaf area because of the high energy costs and nutrient requirements associated with their production and maintenance (Geoffrey \& Kerstin, 2017).

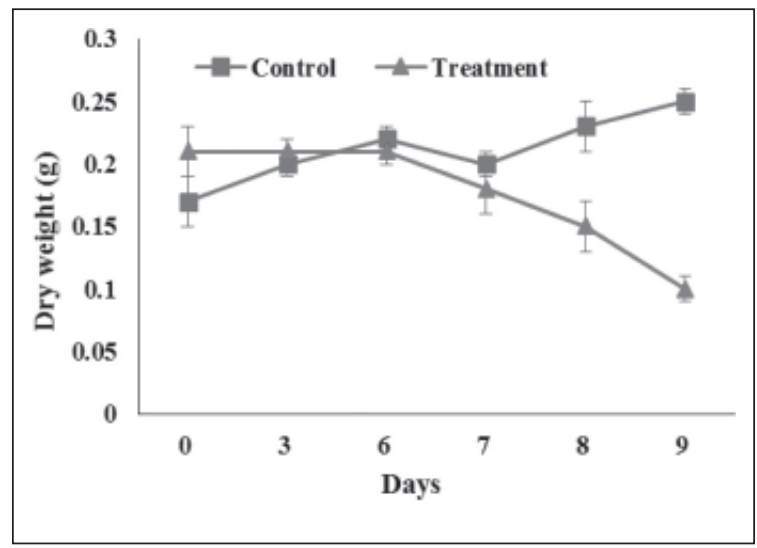

Fig. 5. Changes in dry weight (g) of Phalaenopsis hybrids inoculated with $R$. solani and control. Data are means \pm standard errors $(n=3)$. 


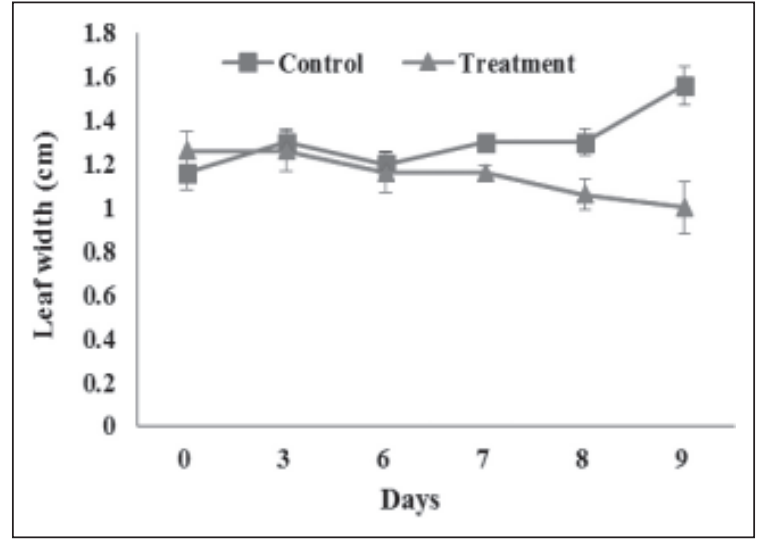

Fig. 6. Changes in leaf width $(\mathrm{cm})$ of Phalaenopsis hybrids inoculated with $R$. solani and control. Data are means \pm standard errors $(n=3)$.

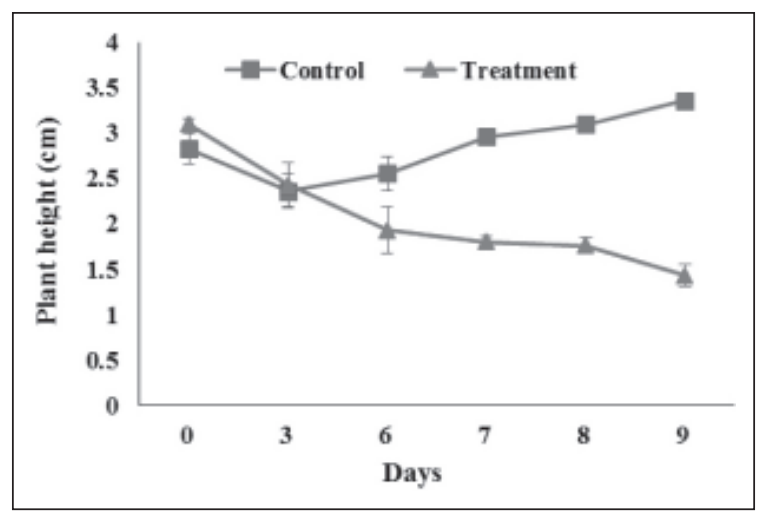

Fig. 8. Changes in plant height $(\mathrm{cm})$ of Phalaenopsis hybrids inoculated with $R$. solani and control. Data are means \pm standard errors $(n=3)$.

The results of plant height in this study (Figure 8) were in agreement with the research by Taheri and Tarighi (2011), who reported that $R$. solani infection significantly reduces the height of tomato plants. This may owe to a pathogenic fungus infection that leads to a reduction of shoot growth would inhibit cell division and expansion. Besides, the reduction of plant height might as well related to some phenolic and glucosidic phytotoxic substances produced by the pathogen and involved in the inhibition of plant shoot growth. Consequently, the above symptoms in the infected plants including low plant growth, leaf area, and dry matter accumulation, followed by tissue wilting, and finally plant death might be due to the energy demands of the host-parasite interaction (ChávezArias et al., 2019).

\section{Effect of Rhizoctonia solani inoculation on chlorophyll content of Phalaenopsis hybrid}

The chlorophyll content in control plants was constant at the earlier stage of inoculation and

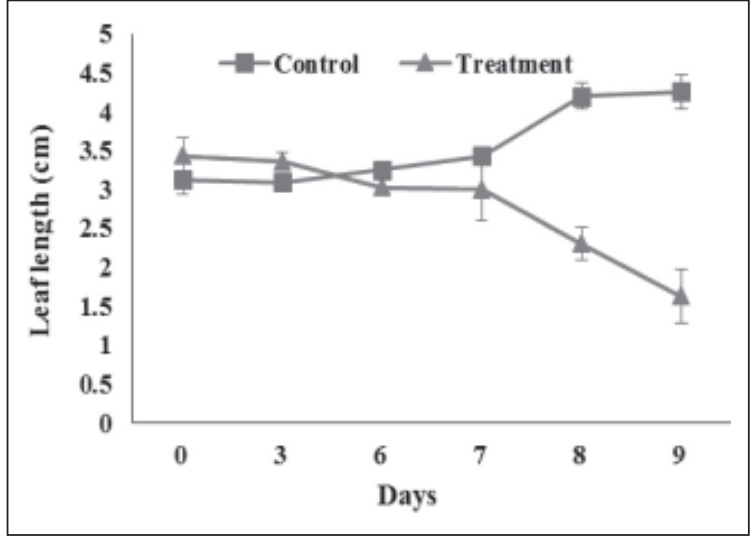

Fig. 7. Changes in leaf length $(\mathrm{cm})$ of Phalaenopsis hybrids inoculated with $R$. solani and control. Data are means \pm standard errors $(n=3)$.

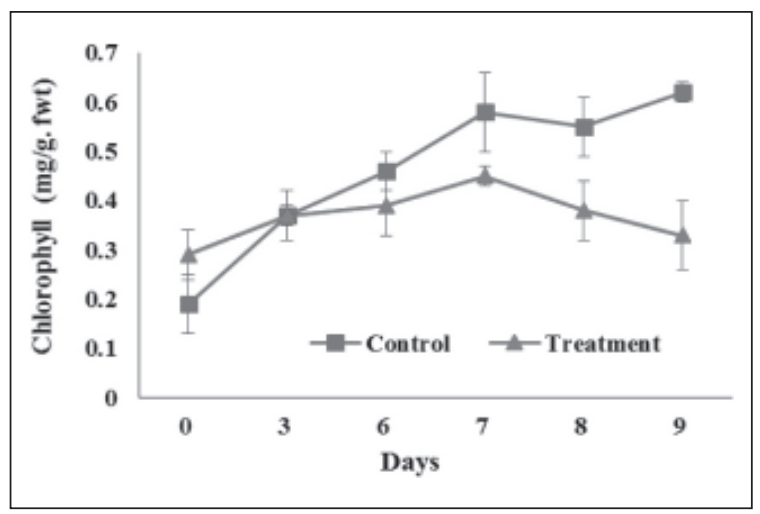

Fig. 9. Changes in chlorophyll content (mg/g.fwt) of Phalaenopsis hybrids inoculated with $R$. solani and control. Data are means \pm standard errors $(n=3)$.

slowly increase at the later stage of the experiment. A different pattern of responses was observed in inoculated plants, where the chlorophyll content was significantly depleted $(p<0.05)$ after 7 days (Figure 9). These results suggest that plants switch off photosynthesis and another assimilatory metabolism to initiate respiration coupled with other processes required for defense (Berger et al., 2007). A decline in $9 \%$ leaf photosynthesis was also spotted in sunflower hybrid after 66 days of inoculation with $V$. dahliae (Sandras et al., 2010). Also, Berger et al. (2007) described similar results in Phaseolus vulgaris plant infected by Colletotrichum lindemuthianum race 23. A low leaf chlorophyll content in this study may be because $R$. solani can produce a pathogenicity factor, which alters the plant's metabolism and favors leaf photosynthetic pigments degradation as observed in Physalis Peruviana L. against F. oxysporum (Wu et al., 2008). 


\section{CONCLUSION}

The results of this study indicated that the type of interaction between the Phalaenopsis hybrid with $R$. solani is pathogenic. Rhizoctonia solani manages to inhibit Phalaenopsis hybrids growth by reducing its fresh and dry weights as well as decrease the leaf area and plant height. The decrease in chlorophyll content was subsequently reduced the dry biomass. It is interesting to explore whether $R$. solani can play roles as mycorrhiza at different growth stages of Phalaenopsis hybrid especially during seed germination, protocorm emergence as well as a young seedling.

\section{ACKNOWLEDGEMENTS}

The authors wish to acknowledge the Malaysian Government for the financial supports under the FRGS grant (vote no 59476) and all the parties involved especially from the Faculty of Science and Marine Environment, UMT.

\section{REFERENCES}

Abdeljalil, N.O.B., Vallance, J., Gerbore, J., Bruez, E., Martins, G., Rey, P. \& Remadi, M.D. 2016. Biocontrol of Rhizoctonia root rot in tomato and enhancement of plant growth using Rhizocbacteria naturally associated to tomato. Journal Plant Pathology \& Microbiology, 7(6): 356-364.

Agarwai, D.K. 2010. Rhizoctonia D.C: Taxonomy, ecology and management. In: Taxonomy and Ecology of Indian Fungi. K.G. Mukerji and C. Manoharachary (Eds.). I K International Publishing House, New Delhi. pp. 19-49.

Aung, K., Jiang, Y. \& He, S.Y. 2018. The role of water in plant-microbe interactions. The Plant Journal, 93: 771-780.

Berger, S., Sinha, A.K. \& Roitsch, T. 2007. Plant physiology meets phytopathology: plant primary metabolism and plant pathogen interactions. Journal of Experimental Botany, 58(15): 4019-4026.

Borges, L.L., Santana, F.A., Castro, I.S.L., Arruda, K.M.A., Ramos, H.J.D., Moreira, M.A. \& de Barros, E.G. 2013. Differentially expressed proteins during an incompatible interaction between common bean and the fungus Pseudocercospora griseola. Molecular Breeding, 32: 933-942.

Brundrett, M. 2004. Diversity and classificationof mycorrhizal associations. Biological Reviews, 79: 473-495.
Chávez-Arias, C.C., Gómez-Caro, S. \& Hermann Restrepo-Díaz, H. 2019. Physiological, biochemical and chlorophyll fluorescence parameters of Physalis peruviana L. seedlings exposed to different short-term waterlogging periods and Fusarium wilt infection. Agronomy, 9: 213-233.

Daami-Remadi, M., Zammouri, S. \& Mohamed, E.M. 2008. Effect on the level of seed tuber infection by Rhizoctonia solani at planting on potato growth and disease severity. The African Jounal of Plant Science and Biotechnology, 2(1): 34-38.

Dearnaley, J.D.W., Martos, F. \& Selosse, M.A. 2012. Orchid mycorrhizas: molecular ecology, physiology, evolution and conservation aspects. Fungal Association, 9: 207-230.

Debona, D., Rodrigues, F.A., Rios, J.A., Martins, S.C.V., Pereira, L.F. \& DaMatta, F.M. 2014. Limitations to photosynthesis in leaves of wheat plants infected by Pyricularia oryzae. Phytopathology, 104: 34-39.

Geoffrey, O. \& Kerstin, W. 2017. Advances in plant tolerance to biotic stresses. Intech Open Science, 8(2): 67-81.

Harbone, J.H. 1984. Phytochemical Methods. 2nd Ed. Chapman and Hall, New York.

Herrera, H., Valadares, R., Contreras, D., Bashan, Y. \& Arriagada, C. 2017. Mycorrhizal compatibility and symbiotic seed germination of orchids from the Coastal Range and Andes in south central Chile. Mycorrhiza, 27: 175-188.

Hossain, M.M., Kant, R., Van, P.T., Winanto, B., Zeng, S. \& James, A.T.D. 2013. The application of biotechnology to orchids. Review Plant Science, 32: 69-139.

Larone, D.H. 1995. Medically Important Fungi: A Guide to Identification. Washington DC: ASM Press.

Lemoine, R., Camera, S.L., Atanassova, R., Dédaldéchamp, F., Allario, T., Pourtau, N., Bonnemain, J.L., Laloi, M., Coutos-Thévenot, P., Maurousset, L., Faucher, M., Girousse, C., Lemonnier, P., Parrilla, J. \& Durand, M. 2013. Source-to-sink transport of sugar and regulation by environmental factors. Frontiers in Plant Science, 4: 272-292.

Lucas, J.A. 1998. Plant Pathology and Plant Pathogens. Blackwell Science, Oxford.

Mendgen, K., Hahn, M. \& Deising, H. 1996. Morphogenesis and mechanisms of penetration by plant pathogenic fungi. Annual Review Phytopathology, 34: 367-386. 
Mitra, S. \& Baldwin, I.T. 2014. RuBPCase activase (RCA) mediates growth-defense trade-offs: silencing RCA redirects jasmonic acid (JA) flux from JA-isoleucine to methyl jasmonate (MeJA) to attenuate induced defense responses in Nicotiana attenuata. New Phytologist, 201: $1385-1395$.

Moudi, M., Go, R., Yien, C.Y.S. \& Saleh, M.N. 2013. A review on molecular systematic of the genus Dendrobium Sw. Acta Biologica Malaysiana, 2(2): 71-78.

Mosquera-Espinosa, A.T., Bayman, P., Prado, G.A., Gómez-Carabalí, A. \& Otero, J.T. 2013. The double life of Ceratobasidium: orchid mycorrhizal fungi and their potential for biocontrol of Rhizoctonia solani sheath blight of rice. Mycologia, 105(1): 141-150.

Ogoshi, A. 1975. Grouping of Rhizoctonia solani Kühn and their perfect states. Review of Plant Protection Research, 8: 93-103.

Ovando, I., Damon, K., Bello, R., Ambrosio, D., Albores, V., Adriano, L. \& Salvador, M. 2005. Isolation of endophytic fungi and their mycorrhizal potential for the tropical epiphytic orchids Cattleya skinneri, C. aurantiaca and Brassavola nodosa. Asian Journal of Plant Sciences, 4(3): 305-315.

Parthibhan, S., Rao, M.V. \& Kumar, T.S. 2017. Culturable fungal endophytes in shoots of Dendobium aqueum Lindley-An imperilled orchid. Ecological Genetics and Genomics, 3(5): 18-24.

Peterson, R.L., Massicotte, H.B. \& Melville, L.H. 2004. Mycorrhizas: Anatomy and Cell Biology. National Research Council Research Press, Ottawa.

Quoc, N.B. \& Chau, N.N.B. 2017. The role of cell wall degrading enzymes in pathogenesis of Magnaporthe oryzae. Current Protein Peptide Science, 18(10): 1019-1034.

Rasmussen, H.N. \& Rasmussen, F.N. 2009. Orchid mycorrhiza: implications of a mycophagous life style. Oikos, 118: 334-345.
Sandras, V.O., Quiroz, F., Echarte, L., Escande, A. \& Pereyra, V.R. 2010. Effect of Verticillium dahlia on photosynthesis, leaf expansion and senescence of field grown sunflower. Annals of Botany, 88: 1007-1015.

Shabariah, I. 2017. Introduction floriculture industry in Malaysia, in: 69 $9^{\text {th }}$ AIPH Annual Congress, 25th-29th September 2017. Taichung, Chinese, Taipei.

Suryantini, R., Wulandari, R.S. \& Kasiamdari, R.S. 2015. Orchid mycorrhizal fungi: Identification of Rhizoctonia from West Kalimantan. Microbiology Indonesia, 9(4): 157-162.

Sweet, C.L. \& Uchida, J.Y. 2015. Characterization of emerging Fusarium diseases on commercially grown orchids in Hawaii. Plant Pathology, 64(3): 648-654.

Taheri, P. \& Tarighi, S. 2011. Cytomolecular aspects of rice sheath blight caused by Rhizoctonia solani. European Journal of Plant Pathology, 129: 511-528.

Yamazaki, J. \& Miyoshi, K. 2007. In vitro asymbiotic germination of immature seed and formation of protocorm by Cephalanthera falcata (Orchidaceae). Annals of Botany, 98(6): 1197-206.

Yao, M.K., Tweddell, R.J. \& D•silets, H. 2002. Effect of two vesicular-arbuscular mycorrhizae: Fungi on the growth of micropropagated potato plantlets and on the extent of disease caused by Rhizoctonia solani. Mycorrhiza, 12(5): 235-242.

Yeh, C.M., Chung, K., Liang, C.K. \& Tsai, W.C. 2019. New insights into the symbiotic relationship between orchids and fungi. Applied Sciences, 9: 585-598.

Wu, H.S., Raza, W., Fan, J.Q., Sun, Y.G., Bao, W., Liu, D.Y. \& Miao, W.G. 2008. Antibiotic effect of exogenously applied salicylic acid on in vitro soilborne pathogen. Fusarium oxysporum f. sp. niveum. Chemosphere, 74: 45-50. 